\title{
The greying of a rainbow nation: Policy responses to the implications of population ageing in South Africa
}

\author{
Wade Goodrick ${ }^{1}$ and André Pelser ${ }^{2 \$}$ \\ ${ }^{1}$ University of the Free State, Bloemfontein, South Africa, Tel: 051401 9258, Fax: 0514013518 , \\ Email: goodrickwf@ufs.ac.za \\ ${ }^{2}$ University of the Free State, Bloemfontein, South Africa, Tel: 051401 2653, Fax: 051401 3518, \\ Email: pelseraj@ufs.ac.za
}

\begin{abstract}
The South African population is set to experience significant ageing in the decades to come; reaching the stage of having a formally 'aged' or 'old' population by 2025. This looming yet profound demographic change is already impacting in certain sectors and will place numerous pressures on many socio-economic and developmental fronts, requiring the reconfiguration of the country's development agenda, aims, programmes and policy. Drawing on both quantitative and qualitative data, this paper explores the demographic nature and socio-economic challenges of the ageing transition in South Africa and suggests some guidelines to improve policy responses targeting the implications of ageing. The paper concludes that South Africa will face a plethora of implications and challenges associated with population ageing, and recommends that further impetus be focused on enhancing programmes that facilitate the awareness of ageing implications as well as the mainstreaming of ageing concerns in public policy. Furthermore, more progressive research on the potential implications of ageing in a South African context should be initiated. $\square$
\end{abstract}

Keywords: Ageing; ageing transition; ageing policy; challenges and implications

\section{Résumé}

Dans les prochaines décennies, la population sud-africaine va vivre un vieillissement considérable. Ce changement démographique, menaçant et profond, s'établit déjà dans certains secteurs et mettra de possibles pressions au niveau socio-économique et sur l'agenda développemental du pays (incluant les objectifs, les programmes et les politiques publiques) qui devra donc être reconfiguré. En utilisant des informations qualitatives et quantitatives, cet article examine la nature démographique et les défis socioéconomiques de la transition démographique en Afrique du Sud, et suggère quelques directives afin d'améliorer les politiques publiques visant à pallier aux conséquences de ce vieillissement. En conclusion, cet article recommande ainsi que l'élan futur doit se concentrer sur l'amélioration des programmes facilitant la sensibilisation aux conséquences du vieillissement, mais aussi les prenant en compte dans les politiques publiques. En outre, des recherches plus progressistes doivent être initiées à ce sujet.

Mots-clés: vieillissement; transition démographique; politiques publiques de vieillissement; défis et conséquences

\footnotetext{
\$Corresponding Author
} 


\section{Introduction}

The human population on our planet has been marked by truly staggering growth over the past 100 years: From a "modest" I.6 billion people in 1900 to more than seven billion by 20II (UNDESA 20I3). The South African population too has seen unprecedented growth, growing from less than six million in 1911 to more than 50 million in $201 \mathrm{I}$ - an increase of $747 \%$ over the past 100 years (SAIRR $20 \mathrm{II}$ ). While rapid population growth (particularly in developing countries) dominated international demographic agendas and developmental policies for much of the past few centuries, in recent times a new demographic trend has emerged to feature in $21^{\text {st }}$ century populations, i.e. the ageing of populations. As detailed in the World Ageing Report (UNDESA 2009), in 1950 there were only 205 million persons aged 65 and older throughout the world; by 2009 the world had 737 million older persons. Consequently, it is projected that the global population of persons aged 65 and older will increase threefold to reach 2 billion by 2050 . While this trend is most evident in the more developed regions of the world, less developed nations such as South Africa have also begun to experience significant amounts of ageing. From a mere 490000 persons aged 65 and older in 1950, South Africa is now home to over 2.7 million older persons, and will be home to 5.7 million by 2050 (UNDESA 2013; SAIRR 2012). Implications of ageing vary from country to country, but on average produce several social, economic, environmental and political challenges that all require specific policy interventions, along with some opportunities.

While numerous studies have analysed policy responses to ageing in the more developed regions, far less concern has been directed towards ageing in the developing countries - including South Africa. Where evident, research on ageing in South Africa has mostly consisted of descriptive studies aiming to explore the proportions and nature of ageing amongst the main racial groups of the "rainbow nation" (ILC 2009; MacFarlane 2005). A further troubling aspect is the tendency for most studies to only explore the implications of population ageing, but not to consider the application of successful policy responses and solutions to ageing (Joubert \& Bradshaw 2006). Therefore, in response to a perceived gap in analysis pertaining to the South African policy responses targeting the implications of population ageing, this paper aims to address the 649 following question: To what extent do socioeconomic and developmental policy frameworks in South Africa take the implications of and challenges posed by population ageing into consideration? Using both quantitative and qualitative data, this paper reports on the findings of a study that sought to analyse and assess South Africa's policy responses to population ageing in the country.

\section{Data and methods}

To effectively approach the topic under investigation, both secondary quantitative data and primary qualitative data were collected. To study the nature of population ageing in South Africa quantitatively, in-depth literature reviews and secondary demographic projections based on data primarily supplied by the United Nations Department of Economic and Social Affairs: Population Division (UNDESA) and the South African Census 201I were used. UNDESA was used as a primary source due to UNDESA using data collected by several public and private sources that include Statistics South Africa, the NGO Age-inAction and several national departments that included the South African Department of Social Development. With reference to the demographic data used in this study, all projections were based upon medium and normal variant assumptions when dealing with the levels and future paths of fertility, mortality and migration. These demographic projections allowed for reflection on past and potential future ageing trends across the globe.

Primary qualitative data was generated by conducting semi-structured telephonic interviews with key and strategic stakeholders actively working with ageing policy and the associated implications and challenges of ageing in South Africa. These stakeholders were located in various developmental units and governmental departments in South Africa, which included the Department of Social Development (Sub-Programme: Care and Services to Older Persons), and the non-government organization (NGO) Age-in-Action: South African division. The research participants were relevant to the study as they all serve in an executive capacity dealing with the needs, concerns and services associated with the growing older population in the country. Research participants were selected by means of purposive and snowball sampling. However, due to the very limited number of persons working directly with policy related issues of ageing in South Africa, this part of the study was 
restricted to only four key respondents. These interviews drew upon the research participants' professional opinions to identify important positions regarding the implications of population ageing in South Africa, while also exploring and assessing the country's policy responses to population ageing. Overall, policy analysis was used to identify past failures, gaps and successes of various responses to ageing in South Africa, while recommending future policy changes.

\section{On the nature and extent of population} ageing

Arguably one of the most predominant demographic concerns of the $21^{\text {st }}$ century, population ageing has come to dominate much of socio-economic and developmental thinking. Although several descriptive and technical definitions of the concept exist, in this paper population ageing refers to demographic changes in a population's age structure that result in the growth of the number and proportion of persons aged 65 years and older (Weeks 2012). Populations age most progressively once they have experienced lengthy periods of both fertility and mortality decline simultaneously. This results in proportions of both children and adults of working age declining, while the elderly proportion rises.

Technically and demographically some analysts define an "old" population as one with $7 \%$ and more of its population aged 65 years and older (Pelser 2012); others, however, state that a truly "aged" population is comprised of $14 \%$ or more older persons (Eberstadt \& Groth 2010). South Africa has shown significant progression through the ageing transition, having had $3.9 \%$ of the population aged 65 years and older in 1960 and now having approximately $5.6 \%$ (Census 20I I; UNDESA 20I3). However, in comparison to the different developmental regions across the world the country is ageing faster than least developed regions, but is ageing slower than less and more developed regions as depicted in Table I.
Table I: Number and proportion of people 65 years and older per developmental region and South Africa (1960-2050)

\begin{tabular}{|c|c|c|c|}
\hline $\begin{array}{c}\text { Developmental } \\
\text { regions }\end{array}$ & Year & $\begin{array}{c}\text { Proportion } \\
(\%) \text { of } \\
\text { people aged } \\
65 \text { years } \\
\text { and older }\end{array}$ & $\begin{array}{c}\text { Number } \\
\text { of people } \\
\text { aged } 65 \\
\text { years and } \\
\text { older } \\
\text { (millions) }\end{array}$ \\
\hline \multirow{5}{*}{$\begin{array}{c}\text { More } \\
\text { developed } \\
\text { regions }\end{array}$} & 1960 & 7.9 & 63.9 \\
\hline & 1985 & 11.7 & 129.9 \\
\hline & 2010 & 15.9 & 197.0 \\
\hline & 2035 & 23.5 & 306.5 \\
\hline & 2050 & 25.7 & 337.2 \\
\hline \multirow{5}{*}{$\begin{array}{l}\text { Less developed } \\
\text { regions }\end{array}$} & 1960 & 3.6 & 75.8 \\
\hline & 1985 & 4.3 & 161.2 \\
\hline & 2010 & 5.8 & 327.3 \\
\hline & 2035 & 11.2 & 820.2 \\
\hline & 2050 & 14.7 & $1,173.3$ \\
\hline \multirow{5}{*}{$\begin{array}{c}\text { Least } \\
\text { developed } \\
\text { regions }\end{array}$} & 1960 & 3.0 & 7.2 \\
\hline & 1985 & 3.1 & 14.0 \\
\hline & 2010 & 3.4 & 28.4 \\
\hline & 2035 & 5.0 & 68.2 \\
\hline & 2050 & 7.0 & 121.6 \\
\hline \multirow[t]{5}{*}{ South Africa } & 1960 & 3.9 & 0.67 \\
\hline & 1985 & 3.1 & 1.03 \\
\hline & 2010 & 5.6 & 2.7 \\
\hline & 2035 & 8.0 & 4.8 \\
\hline & 2050 & 10.5 & 6.7 \\
\hline
\end{tabular}

Source: Constructed with data from SAIRR 2012 \& UNDESA 2013

As illustrated in Table I, the more developed regions have experienced the most significant extent of ageing, while many of the less and least developed countries have only just begun to experience the ageing transition in full. However, the less and least developed regions are catching up in terms of progression throughout the ageing transition. On average, the most rapid increases in older populations are occurring in the less developed world, where it is projected that between 2006 and 2030 , the number of older persons in less developed countries will increase by $140 \%$, as compared to an increase of $51 \%$ in the more developed countries (Powell, 20II). By 20I0, only the more developed regions were characterised by having "old" populations, with more than $14 \%$ of their populations aged 65 years and older (UNDESA 20I3). Comparatively, $5.8 \%$ of the populations in the less and least developed regions were aged 65 years and older. With regards to absolute numbers 
of elderly, the less developed regions - because of their overall superiority in total population numbers - have far more elderly than the more and least developed regions (see Table I). All in all, such significant increases in proportion and number of elderly warrant responses from socio-economic and developmental planners and policy makers.

\section{International policy responses targeting the implications of an ageing society}

The implications triggered by ageing fall into a series of social, economic, environmental and political challenges and opportunities that all require careful policy considerations and intervention. The discussion and illustration of such implications are prevalent throughout social policy and ageing literature (see Malmberg et al. 2006; Powell 20I I; Vos et al. 2008 \& Weeks 2012 for in-depth discussions of implications), but the sheer complexity of these challenges is often overlooked. One example of such implications associated with population ageing, and one that has garnered much attention in more developed countries in particular, is the likelihood that social expenditure will increase as more people age and require social support from age-sensitive state social security systems, due to the escalating numbers of pension recipients and longer durations of eligibility (Powell 201 I). While these and many other implications of ageing will occur in almost all countries (Leahy 20I0), such implications will likely occur differently from country to country due to the ageing transition differing amongst dissimilar economies. However, all countries will have to respond to the implications of population ageing at one point or another.

Overall, the challenges unleashed by population ageing are not insurmountable as long as strong, comprehensive and integrated policy responses are implemented in order to facilitate, inform and enable sustainable and functioning ageing societies. Such policy responses have been widely encouraged by two international ageing plans of action: i) the Vienna International Plan of Action (1982) that was focused on policies in the more developed nations that tended towards a welfare orientation and ii) the 2002 Madrid International Plan of Action on Ageing (2002). The MIPAA is an evolution in the approach to social policy, aiming to produce enabling and supportive environments by using the MIPAA's guiding framework (UNDESA 2002). It is largely agreed (Bloom et al. 2007; Velkoff \& Kowal 2007), that without such policy responses and a suitable policy environment, countries will likely be too slow to adapt to their changing age structures, and miss the benefits provided by the associated opportunities of having an ageing population. Past policy responses targeting the implications of population ageing have shown that specific areas require attention, namely: i) social expenditure policy responses that focus on creating more beneficial and befitting environments for successful ageing, provision of healthcare and support to elderly persons and creating sustainable settings in which to make pension payments to all persons requiring them; ii) economic policy responses that focus upon attaining greater participation in an increasingly smaller labour force, redesigning and restructuring the nature of work to be more accessible and comfortable for older workers, and attaining the funds required for social expenditure through means of taxation or resources obtained from securing the demographic dividend; iii) demographic policy responses, such as the adoption of pro-natalist and replacement migration polices which encourage direct transformations in population age structures; and lastly, iv) political policy responses which establish specific ageing committees that regulate the implementation and measurement of policy responses targeting the elderly and population ageing.

Most policies dealing with the adaptation to population ageing currently exist in the more developed regions of the world and relatively few in the lesser developed regions (Blair 2009; Mirkin \& Weinberger 2000; UNDESA 2002). However, this is changing as more nations begin to age and experience the effects of the ageing transition and thus are compelled to respond to such challenges. South Africa is no exception to this trend.

\section{Results and discussion}

This section discusses the state of population ageing in South Africa by illuminating the main features of the ageing transition in South Africa, identifying the most pressing implications and challenges unleashed by an ageing South African population, as well as assessing the suitability and appropriateness of current South African ageing policy.

The nature and magnitude of population ageing in South Africa

Best described as a microcosm of demographic change, South Africa is characterised by a population 
that still comprises a built-in momentum for future increases in population size (Department of Social Development 2010). Nevertheless, due to the iterative combination of mortality and fertility declines, the ageing transition in South Africa has produced marked increases in the proportions of adult and older persons in conjunction with declining numbers of younger persons from roughly the early 1980s and onwards. Overall, the South African population of 65 years and older has increased from $3.6 \%$ of the total population in 1950 to $5.2 \%$ in 2010 and is expected to grow to $10.5 \%$ by 2050 and culminate in over $20 \%$ by the end of the current century (UNDESA 20I3). In fact, the age group 65 years and older is the only age cohort in the South African population that is projected to show consistent and continuous growth in the decades to come (Pelser 2012; UNDESA 2013).

Figure I: $\quad$ Population pyramids of South Africa, 1950-2100
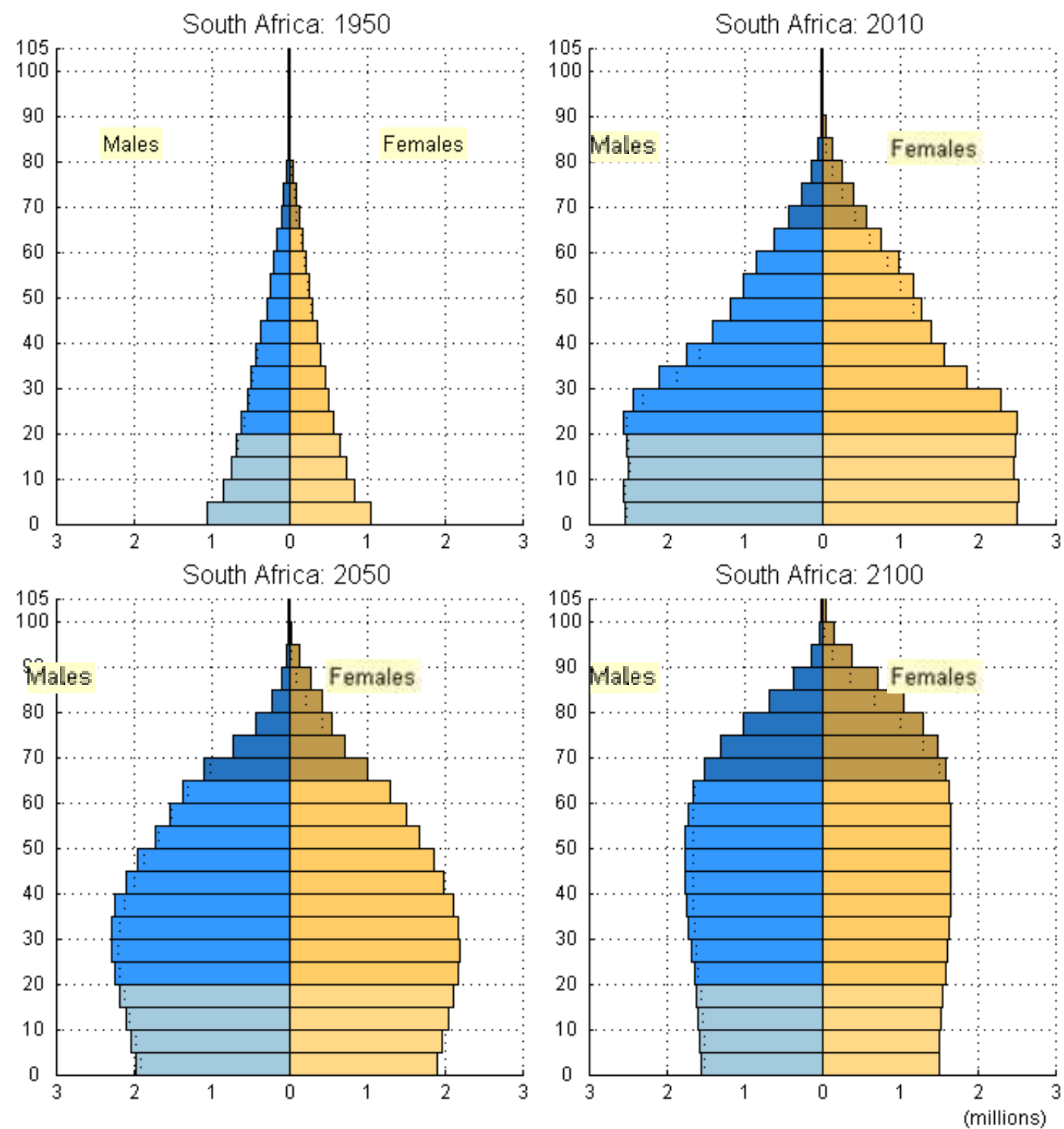

Source: UNDESA 2013

The South African population has experienced significant mortality declines since the 1950s, dropping from as much as 20 deaths per 1000 people of the population in 1950 to as low as 8 deaths per 1000 people of the population in 1995 before an HIV/AIDS induced reversion to higher mortality rates set in after 1995 (Department of Social Development 1998; MacFarlane 2005). 
Mortality declines initiated the ageing transition by producing celebrated improvements in South African life expectancies, where overall life expectancy significantly improved from a mere 45 years in the 1950-1955 period, to 61.2 years in the 1990-1995 period (UNDESA 2013). These improvements in life expectancy allowed for the initial ageing of the South African population, as improved longevity influenced much of the growth in the absolute numbers of older persons from 490000 elderly in 1950 to 1.4 million elderly in 1995 (UNDESA 2013). However, this trend of improving life expectancies was cut short in the mid-1990s due to the HIV/AIDS pandemic generating high rates of mortality. Subsequently, life expectancy gains were reversed in a few years, dropping from an all-time high of 61.2 years for both sexes in the 1990-1995 period, to a low 52.3 years during the 2000-2005 period (UNDESA 20I3).

With regard to fertility declines associated with ageing, South Africa's fertility rate rapidly dropped since the 1970s, eventually reaching an approximate 2.5 children per woman in 2010 , and is projected to drop further to replacement level by approximately 2017 (UNDESA 2013). As a result of lengthy declines in both mortality and fertility over the same period, proportions of both children and adults of working age have been declining, while the elderly population has invariably grown (Vos et al. 2008). As illustrated in Figure I, the proportion and size of both the elderly cohort and the younger cohorts in South Africa have been and will continue to change and become progressively more mature.

Figure I shows that, by approximately 2050, South Africa will have become an "old" population a remarkable achievement as it will be one of the first African countries to do so (Smith \& Mensah 2003). It is further projected that South Africa will have more elderly persons than younger persons by the year 2100 , with approximately $17 \%$ of the population falling into the age cohort of $0-14$ years, compared with an estimated $21.7 \%$ contribution of the elderly to the total population (UNDESA 20I3). As illustrated in Table 2, the different South African population groups are all experiencing population ageing, albeit at different rates and degree of ageing.

Table 2 shows that the African population group has the largest number of elderly persons (I 796 23I), while the other population groups have significantly smaller older populations. Furthermore, comparing the numbers of male elderly to female elderly shows that there were 720860 more female elderly than male elderly in 20II. One reason for such an occurrence is due to female life expectancy being significantly higher than that of male life expectancy in South Africa (SAIRR 2012). Regarding life expectancy at birth by race, the Coloured, Indian/Asian and White groups have shown consistent improvements.

Table 2: Demographic characteristics of South African older population (65 years and older) per population group, $201 \mathrm{I}$

\begin{tabular}{|c|c|c|c|}
\hline \multicolumn{4}{|c|}{$\begin{array}{l}\text { Age profile (number of older persons) by race and } \\
\text { sex, } 201 \mathrm{I}\end{array}$} \\
\hline Population group & Total & Male & Female \\
\hline African & 1796231 & 624179 & 1172052 \\
\hline Coloured & 217907 & 86679 & 131228 \\
\hline Indian/Asian & 88949 & 37383 & 51566 \\
\hline White & 649686 & 282083 & 367603 \\
\hline Total & 2793992 & 1036566 & 1757426 \\
\hline \multicolumn{4}{|c|}{ Life expectancy at birth by race, $2000-2025$} \\
\hline Population group & 2000 & 2010 & 2025 \\
\hline African & 55.9 & 55.8 & 57.1 \\
\hline Coloured & 63.2 & 64.0 & 64.9 \\
\hline Indian/Asian & 67.4 & 68.5 & 69.9 \\
\hline White & 72.1 & 72.5 & 72.9 \\
\hline Total & 58.3 & 58.2 & 59.1 \\
\hline \multicolumn{4}{|c|}{ Old-age dependency ratio by race, $2000-2040$} \\
\hline Population group & 2000 & 2010 & 2040 \\
\hline African & 6.7 & 7.4 & 16.6 \\
\hline Coloured & 5.5 & 7.0 & 21.5 \\
\hline Indian/Asian & 6.6 & 10.4 & 28.3 \\
\hline White & 15.2 & 19.4 & 41.9 \\
\hline Total & 7.5 & 8.6 & 19.0 \\
\hline
\end{tabular}

Source: Constructed with data from SAIRR 2012

However, the African population group has not experienced as much progress as the others largely as a result of high HIV prevalence rates. However, it is projected that life expectancy will improve throughout the country as HIV prevalence rates decline with better access to ARV (Antiretroviral) treatment (SAIRR 20I2). Lastly, the differing old-age dependency ratios for population groups divide the country into three groups. The African old-age dependency ratio is characteristic of a young population with a small proportion of elderly, while the Coloured and Indian/Asian groups are increasingly showing their progress towards having mature populations. Moreover, the White population group has the highest dependency ratio 
and will come to resemble similar characteristics of the oldest populations in the coming decades. Projections pertinently illustrate that while all groups are ageing, there are considerable differences between the oldest and youngest groups. Irrespective of how the South African population progresses through the ageing transition, the country will experience a variety of implications, challenges and opportunities associated with population ageing.

\section{The implications of an ageing South African population}

A number of implications associated with population ageing have come to define much of the policy and developmental responses of developed countries in the last half century. The implications associated with population ageing in a developing country such as South Africa are nevertheless highly significant and of great importance, even though the profound implications are bound to be less well appreciated due to the predominance of issues related to the county's previous younger population age structure, i.e. HIV/AIDS and youth dependency. There are at least five particular implications associated with ageing which South Africa will likely face, all of which will pose immense challenges for the country in the years to come.

Firstly, increased demand for adequate housing for the older population will present a major challenge. As clarified by respondents, a lack of prioritised housing specific to older persons has led to many still fully independent older persons entering old age homes when they cannot find affordable housing elsewhere or cohabiting in extended households. Irrespective of just providing housing for older persons, South Africa continues to grapple with the challenge of providing enough housing for its citizens. Between 1997 and 201I, only 805245 housing units were completed by the private sector and 2979703 housing units completed by government (SAIRR 20II). Notwithstanding these efforts, the housing backlog has not declined but rather continued to escalate in the last two decades. As a result of persistently high rural-urban migration and rapid household formation, the required number of houses increased from 1.9 million units in 1996 to 2.2 million in 2008 (Department of Social Development 2008). Government has stated that this backlog must be erased by 2030 (SAIRR 20II). Erasing the backlog will prove challenging when also providing for elderly persons who wish to live outside of their extended families. By 2012, 56.3\% of the South African population were living in extended households, many of which are expected by government to include older persons.

Secondly, the increased need of financial support (old-age grants and pensions etc.) for a growing older population will pose an immense challenge to South Africa. The number of old-age pension recipients has continuously grown over the past two decades - from 1.9 million in $200 \mathrm{I}$ to 2.2 million in 2007 and to over 2.7 million by $201 \mathrm{I}$ (SAIRR 20I2). Such growth is, of course, adding much to the escalation in the total number of social grant recipients. In recent years the total number of social grant recipients has increased by more than one million per year: From 12.3 million recipients in 2008 to 13.7 million in 2010 and 14.9 million in 201 I (SAIRR 20I2). However, a large proportion of older persons are still not receiving old-age pensions. According to SAIRR (2012), in 200I, 61\% of older South Africans were old-age pension beneficiaries. By $201 \mathrm{I}, 77 \%$ of all older South Africans benefited from the old-age pension system. In terms of numbers, South Africa has made strides in increasing the number of old-age pension beneficiaries from 1.9 million in $200 \mathrm{I}$, to 2.7 million 201 I. However, close to 1.2 million older South African are still not receiving any benefits from the old-age pension system (SAIRR 20I2).

Furthermore, South Africa would need more resources on average per older person, as many elderly act as caregivers for their unemployed adult children, their sick family members and their orphaned grandchildren. This point is especially relevant to the Eastern Cape, KwaZulu-Natal and Limpopo provinces who currently have the highest number of social grant beneficiaries (SAIRR 20II).

Thirdly, an increased demand for long-term and chronic healthcare for the growing older population will be inevitable as a result of an overall increase in the absolute numbers of elderly. In addition, increased life expectancy of the elderly will lead to older persons living to ages where healthcare is required over longer periods of time, as well as advanced age, where frailty is common. Most recently, the absolute number of persons aged 65 years and older - that serve as the cohort which tends to exhibit most chronic and long-term healthcare needs - has grown from 2.3 million in 2009 to 2.7 million in 20II (SAIRR 20I2). This 
growth will require the South African government to rethink its frail-care services, especially with regard to the scale of service and resources required for a growing older population.

Furthermore, slower economic growth produced by an economy primarily made up of older workers, workers on the verge of retiring and fewer economically active persons could potentially prove a major challenge to South Africa a nation still trying to achieve high levels of socioeconomic development (Department of Social Development, 2010). A widely publicized fact concerning the economic implications associated with ageing is the fear of declines in economic productivity and growth due to reliance on older workers (Malmberg et al. 2006; Powell 201 I; Vos et al. 2008). Especially when large amounts of elderly may seek to provide for their later years by extending their working lives beyond retirement ages. While South Africa provides for a large number of old-age pension recipients (i.e. 2659470 old-age pension recipients in 201 I), with greater socioeconomic development more and more people will likely find that such a grant is not able to fully provide for their lifestyles (SAIRR 20I2). Thus, elderly South Africans may be forced to become economically active again so as to maintain a sufficient standard of living that meets their expectations. However, older South Africans are likely to be discouraged from extending their working lives due to the fact that the old-age pension is means tested.

Lastly, a declining proportion of economically active persons (15-64 years old) to support the growing number of elderly could pose a challenge to South African society, as the country's noncontributory pension grant is derived from the taxes of the working people, who will steadily decline in number as the population ages (Weeks 2010). Simultaneously, South Africa has been plagued by high numbers of unemployed persons. According to the official definition of unemployment there were 4081000 unemployed South Africans in 2001 - a figure that increased to 4364000 by $201 \mathrm{l}$. Moreover, the proportion of economically active South Africans (aged I5-64 years) has been declining from $60.8 \%$ in 2001 to $54.1 \%$ in 201 I (SAIRR 2012). Such declines in the proportion of economically active workers, coupled with high unemployment, will pose huge challenges as fewer persons will be making tax contributions which have 655 to provide for the needs of the economically inactive parts of the population (persons aged 0-14 and 65 years and older). Respondents in our study noted that as far as the challenges for an ageing population is concerned, this issue would require the most attention from a policy intervention point in the years to come. All five of these implications will impact considerably on South Africa's human development priorities, resulting in many alterations to current social, economic and development agendas. Moreover, the experience of the ageing transition will ultimately depend on the country's overall ability to respond to the many implications and challenges associated with ageing.

\section{South African policy responses to the implications of population ageing}

While the more developed nations of the world have had ample time to grapple with issues and concerns associated with population ageing, South Africa has recently only started to target such concerns by means of socio-economic and developmental policy approaches. Thus far, South Africa's socio-economic policies have been/and are demographically concerned with issues and trends that tend to typify very young and less developed populations (Aboderin 2005). This is rightly so, as the country still contains a large youth bulge in comparison to a relatively small elderly population, which means that the larger dependent youth cohort has thus far attracted greater policy and planning intervention than the smaller elderly population. As illustrated in the National Population Policy (Department of Social Development 1998) and the Progressive Review of the Implementation of The White Paper on Population Policy for South Africa (Department of Social Development 2010), the progressive ageing of South Africa's population has nevertheless been recognised by the South African government.

As a response to the propositions made by the 1994 International Conference on Population and Development (ICPD), South Africa has, along with other actions, sought to enhance the participation of all relevant age groups in South African society. In general, the South African government has adopted the central role of ensuring that the necessary environment, particular to older persons, is created, so that this cohort can make a meaningful contribution to the socio-economic and political development of the country (Department of Social Development 2002). The majority of issues relevant 
to the growing older population are thoroughly incorporated into the South African Policy for Older Persons (2006), which strives to meet the needs of the country's older population. Furthermore, the Implementation Strategy of the Older Persons Act (2006) serves as the chief strategy in which the challenges and implications of population ageing are dealt with. This strategy serves to implement the various aims and goals of the Madrid International Plan of Action on Ageing (MIPAA 2002), but the implementation process of this strategy - since 2010 - has been hindered by several constraints (see Section 5.4). After thorough review, we found that South Africa has developed policy on ageing which focuses on five particular challenges:

Income security and poverty reduction among the older population:Using the Aged Persons Grant, as well as a Grant-in-Aid, South Africa has been committed to the implementation of poverty reduction programmes amongst the elderly population. Since the 1994 democratic elections, the eradication of poverty and inequality has been the primary objective of the South African government, resulting in numerous government initiatives such as the Poverty Relief, Infra-structure and Job Creation Fund, the Integrated Sustainable Rural Development Programme and the Urban Renewal Programme, all of which focus specifically on older persons (Department of Social Development 2002). This concern features extensively in policy, allowing for older persons to receive a source of income. Yet, key and strategic stakeholders in our study indicated that - while the elderly are able to draw upon such a source of income - it is often insufficient to provide the quality of life many older persons seek. Furthermore, the issue of fiscal affordability with regard to pension pay-outs is a major concern, due to South Africa having one of the most generous old age pension systems in the world that will undoubtedly have increased pressures placed upon it as the older population grows in absolute size (Bongaarts 2004). Barrientos (2002) compared pension schemes in several developing countries, and found that South African old-age pension recipients receive considerably more funds in comparison to most other developing nations. However, while this has allowed for a substantial impact on poverty, the system's sustainability is often in question.

Health and wellbeing of older population:Featuring extensively throughout ageing policy, a large number of programmes targeting the healthcare and wellbeing of the older population have been installed. Both primary and secondary healthcare services are inclusive of older persons and available free of charge in many cases to the older population. However, tertiary healthcare services - which see hospitals providing specialist multi-disciplinary care for older persons with complex and multiple chronic conditions for the elderly - tend to be limited. Previous research by Kalula (2010) found that this situation is compounded by few departments of geriatrics existing in South Africa, and few health professionals completing their medical training with adequate exposure to geriatric medicine. Furthermore, our study's respondents noted that policy responses concerning healthcare and wellbeing are only partially effective in meeting the needs of the growing older population. Respondents felt that the lack of effectiveness is largely due to the infancy of important programmes that have only recently taken shape.

Housing and living environments for the older population: A housing subsidy scheme has been developed to provide housing for those persons inclusive of older and disabled persons - who otherwise would not be able to afford it. The South African Government has also sought to provide equal access to residential care for all older and elderly persons; however, this has proved difficult due to i) South African national policy which states that no more than $2 \%$ of the older population may be accommodated in state subsidised facilities, and ii) high costs associated with residential care for older persons (Frail Care Services 2013). In response to the high costs associated with assisted living and residential care facilities, the South African government has encouraged age-in-place initiatives, where older persons should try to remain within the community. More importantly, policy targeting housing and living environments of older persons is felt to be largely ineffective. As communicated by one respondent: "No fact finding procedures were ever engaged in to assess or monitor whether the quota of elderly housing was ever delivered". Furthermore, the provision of housing earmarked for the elderly has been limited due to an immense backlog in in the provision of housing for the broader population that includes the elderly.

Social integration of the older population into society: In order to realise a society for all ages, every age group should be able to participate in the activities of the overall society. To achieve such 
participation, the South African government and non-governmental organisations such as Age-inAction have installed initiatives and developmental programmes that focus on community-based support, enabling volunteerism and community participation among the older population, and creating opportunities for learning and sharing knowledge (Department of Social Development 2002). However, respondents viewed that illiteracy and a lack of sufficient education in the older age groups have served to impede social integration, along with policy that is limited in scope and lacking in resources and service providers to be effectively implemented. More detailed investigations into the magnitude of service provision for older persons are necessary to identify if this is indeed the case.

Promoting the status of older persons:According to respondents,policy pertaining to the "promotion of the status of older persons" only partially features in South African policy. Currently, the development of a Charter on the rights of older persons is being promulgated to strengthen such responses to the concern. The South African government maintains that the status of older persons in South Africa has been strengthened by consultations with older persons made by the Department of Social Development (Department of Social Development 2002).

\section{The limitations and challenges of policy responses targeting the ageing of the South African population}

Various concerns raised by stakeholders in our study suggest that South African policy responses on ageing are hampered by several obstacles that all contribute to the insufficiency of such policy. Firstly, respondents communicated that a lack of data concerning population ageing and the elderly population in South Africa is a persistent problem, due to there being few studies concerning the topic of population ageing in South Africa. Besides, when data is available it is often limited in range and scope. For example, the researchers struggled to find detailed data pertaining to the older population and their many characteristics on a yearly basis. Secondly, respondents felt that policy goals and programmes relating to the elderly prove to be a frustration, as programmes are few and sporadic. While there are relevant existing programmes in place, they are frequently financially inefficient and tend to lack in effective implementation strategy that covers all older persons, monitoring and evaluation 657 tools. In addition, respondents feel that a lack of awareness of population ageing in South Africa among some policy makers has proved challenging and problematic. This may potentially be the result of the older population segment not being treated as a priority, even though they have been recognised as a vulnerable group in the country. One key informant stated that this issue is exacerbated by many policy makers and service providers who are "too relaxed" to notice a cause for concern, and merely view population ageing as a problem of the developed world, not an African issue.

A lack of concern for or interest in the elderly population, or even the population ageing trend in South Africa, has also proved to be a frustration for policy administrators, as the older population may often not be viewed as a major priority in South Africa. Thus, priorities of the elderly are often weighed up negatively against those of the larger and younger population. Overall, the older population may often lose out to socio-economic issues such as poverty, HIV/AIDS and youth dependency that are mostly associated with younger age cohorts. Also, there is a noticeable lack of policy pertaining to the economic implications of having an ageing South African population. Little evidence can be found in policy that identifies responses targeting relevant issues such as a lack of economically active persons that may potentially halt or slow economic growth to the point where a population becomes economically stagnant. This is troubling; as such responses often dominate the ageing policy of more developed nations who have dealt with ageing for extensive periods of time (Murray 2008; Vos et al. 2008). With regards to the actual implementation of ageing policy, the key informants communicated that no single governmental department seemed to be sufficiently resourced or capacitated to deal with the expected challenges that an ageing population will unleash. South African government has put several measures in place to recruit social security personnel to provide for the older population. However, by 2012 , there were only 16740 registered social workers in South Africa; with a population to social worker ratio of 5446 people to one social worker (SAIRR 20I2). Extra pressures on social security personnel have come from high levels of poverty and deprivation, as well as high incidence of HIV/AIDS; resulting in the actual workload per social worker to far exceed the norm. Furthermore, respondents noted that most departments lack skills, 
finances, training, infrastructure and budget allocations to accommodate the mainstreaming of ageing issues and priorities at provincial level, let alone national level.

\section{Conclusions and recommendations}

As an ageing population, South Africa will come to face several challenges. According to the respondents of this study, the most prominent challenges include: increased demand for adequate housing for the older population in the face of housing backlogs; increased need of financial support (old-age grants and pensions etc.) for the growing older population; increased demand for long-term and chronic healthcare for the growing older population; the potential for slower economic growth produced by an economy made up of older workers, workers on the verge of retiring and fewer economically active persons; and a declining proportion of economically active persons (15-64 years old) to support the growing number of older persons. In response to the recommendations provided by the Madrid International Plan of Action (MIPAA), respondents noted that the South African government has been relatively successful in providing a supportive environment where older persons receive sufficient resources and income to sustain a decent quality of life, by targeting income security and poverty reduction amongst the elderly and providing more comprehensive healthcare. However, respondents felt that other areas pertaining to housing and living environments of the elderly and the status of older persons had only been partially successful with much room to improve. Moreover, respondents clarified that a lack of convincing exploratory data, few concise policy programmes, a limited concern for the implications of having an ageing population, and lack of resources and capacity to deal with ageing issues all accumulate in socio-economic policies and frameworks responsible for targeting the older population that are limited in ability, scope and implementation.

To strengthen institutional capacity and position the country for the looming tide of elderly persons, several interventions are required.

I) It is strongly recommended that programmes be implemented that facilitate awareness of the implications, challenges and opportunities associated with population ageing. Such programmes should inform, sensitise and educate national and provincial authorities on all potential impacts produced as a result of the ageing of the South African population and the type of policy interventions that are required to arrest such impacts and capitalise on the opportunities offered by ageing.

2) The South African government should review and improve the drafting and implementation of ageing policy and strategy in South Africa by emphasising policy responses that are readily drafted and realistic in scope and aim, while also emphasising a wider number of impact areas.

3) We further recommend that issues relating to the progressive ageing of the South African population be prioritised in all socio-economic policy by engaging in the mainstreaming of ageing issues. This will best be accomplished by engaging in a collaborative effort amongst governmental departments and NGOs throughout the country that will invest in more detailed and thorough mainstreaming goals. Such a process should be overseen by a coordination committee which engages in cross-departmental analysis and evaluation.

4) We strongly recommend that the South African government and other key and strategic stakeholders initiate and fund research into the socio-economic and macro-economic implications of ageing in South Africa. This research should pertinently evaluate the financial implications of having an ageing population, with an emphasis on housing; healthcare; and social security needs - all of which will have significant monetary implications for the national budget.

Overall, South African authorities have taken steps to generate policy targeting the implications and challenges associated with population ageing, however in some instances there is still a worrying lack of steps taken to fully implement such policy, along with numerous logistical hindrances and institutional arrangement issues. In conclusion, South Africa's policies and frameworks targeting aspects of population ageing are present and active, but still in their infancy.

\section{References}

Aboderin, I. 2005. Understanding and responding to ageing, health, poverty and social change in subSaharan Africa: A strategic framework and plan for research. Oxford: Oxford Institute of Ageing. Barrientos, A. 2002. Comparing pension schemes in Chile, Singapore, Brazil and South Africa. Manchester: University of Manchester. 
Blair, S.N. 2009. Physical inactivity: The biggest public health problem of the $21^{\text {st }}$ century. British Journal of Sports Medicine 43, (I): I-2.

Bloom, D.E. Canning, D. Fink, G and Finlay, J. 2007. Realising the demographic dividend: Is Africa any different? Boston: Harvard University Press.

Bongaarts, J. 2004. Population ageing and the rising cost of public pensions [Online]. Retrieved from: http://www.popcouncil.org [20 August 20I I].

Department of Social Development. 1998. Population Policy. Pretoria: Department of Social Development.

Department of Social Development. 2002. National report on the status of older persons: Report to the Second World Assembly on Ageing. Pretoria: Department of Social Development.

Department of Social Development. 2008. Towards a 10-year review of the Population Policy implementation in South Africa (1998-2008): Overview and introduction. Pretoria: Department of Social Development.

Department of Social Development. 2010. Progress review of the implementation of: the White Paper on Population Policy for South Africa (1998) and the ICDP Programme of Action (1994). Pretoria: Department of Social Development.

Eberstadt, $\mathrm{N}$ and Groth, H. 2010. "The Russian Federation: Confronting the special challenges of ageing and social security policy in an era of demographic analysis." International Social Security Review 63, (3): 23-58.

Frail Care Services. 2013. Frail care database [Online]. Retrieved from: http://www.frailcareservices.co.za [10 November 2013].

International Longevity Centre (ILC). 2009. Global ageing report: Threats to longevity - A call to action. New York: ILC.

Joubert, J and Bradshaw, D. 2006. Growing numbers of older persons in South Africa. Cape Town: MRC Burden of Disease Research Unit.

Kalula, S. 2010. Quality of health care for older persons in South African. Cape Town: Albertina \& Walter Sisulu Institute of Ageing in Africa.

Leahy, E. 20I0. The shape of things to come: Why age structure matters to a safer, more equitable world [Online]. Retrieved from: http://populationaction.org [20 June $20 \mathrm{I}$ I].
MacFarlane, M. 2005. Blight and flight in South Africa's population [Online]. Retrieved from: http://www.sairr.org.za [26 February 20II].

Malmberg, B. Tamas, K. Bloom, D. Munz, R and Canning, D. 2006. Global population ageing, migration and European external policies. Stockholm: Institutet for Framtidsstudier.

Mirkin, B and Weinberger, M.B. 2000.The demography of population ageing. New York: United Nations.

Murray, A. 2008. Growing old gracefully: How to ease population ageing in Europe. London: Centre for European Reform.

Pelser A.J. 20I2. "The health, environment and development nexus in South Africa." In: Van Rensburg HCJ (ed.). Health and health care in South Africa (Second Edition). Pretoria: Van Schaik.

Powell, J.L. 201I. Ageing in Africa [Online]. Retrieved from: http://www.popuec.net [II August 20II].

Smith, S.M and Mensah, G.A. 2003. "Population ageing and implications for epidemic cardiovascular disease in sub-Saharan Africa." Ethnicity \& Disease 13, (I): 77-80.

Socio-economic Rights Institute of South Africa (SERI). 20II. A resource guide to housing in South Africa 1994-2010: Legislation, policy, programmes and practice. Johannesburg: SERI.

South African Institute of Race Relations (SAIRR). 2011. South Africa Survey 2010/2011. Johannesburg: South African Institute of Race Relations.

South African Institute of Race Relations (SAIRR). 2012. South Africa Survey 2012. Johannesburg: South African Institute of Race Relations.

United Nations Department of Economics and Social Affairs: Population Division (UNDESA). 2002. The Madrid International Plan of Action on Ageing: A guiding framework and toolkit for practitioners and policy makers. New York: United Nations.

United Nations Department of Economics and Social Affairs: Population Division (UNDESA). 2009. World population ageing 2009. New York: United Nations.

United Nations Department of Economic and Social Affairs: Population Division (UNDESA). 2013. World population prospects: The 2013 revision [Online]. Retrieved from: 
Vol. 28, No. I: Suppl on Population Issues in South Africa, May, 2014

http://esa.un.org/unpd/wpp/index.htm [16 May Vos, R. Ocampo, J.A and Cortez, A.L. 2008. Ageing $201 \mathrm{I}]$.

Velkoff, V.A and Kowal, P.R. 2007. Population ageing and development. New York: United Nations Publications.

in sub-Saharan Africa: Demographic dimensions. Weeks, J.R. 2012.An introduction to population. Washington DC: National Institute on Ageing. Belmont: Wadsworth Publishing. Declaration:

We confirm that all named authors have contributed sufficiently to the work submitted and that the content of the manuscript has never been previously published. Wade Goodrick was responsible for the first draft of the article, while André Pelser supervised the initial project from which this article emanated and edited the manuscript for this article.

'This article emanated from the following dissertation: Goodrick, W.F. 2012. Policy implications and challenges of population ageing in South Africa. Masters Dissertation, University of the Free State.

ii The provision of housing backlog in South Africa is a major problem for the South African government. It has continued to escalate for almost two decades, as a result of persistently high migration and rapid household formation (Department of Social Development, 2008). By 2007, the Department of Human Settlements (DHS) reported that close to 2.6 million subsidised housing units had been built, benefiting over 10 million people (SERI, 2011). However, delivery of such units has not occurred on an acceptable scale or at a satisfactory pace, with approximately 200000 units built per year since 1994. Regarding the number of houses still required, the backlog has grown exponentially from 1.5 million in 1994 to almost 3 million households in 2010 (SERI, 2011). Importantly, the DHS notes that these numbers are not totally reliable, due to poor provincial and municipal record-keeping, as well as incomplete data concerning housing construction (SERI, 2011). 